\title{
A linguagem trinitária de Gregório de Nissa
}

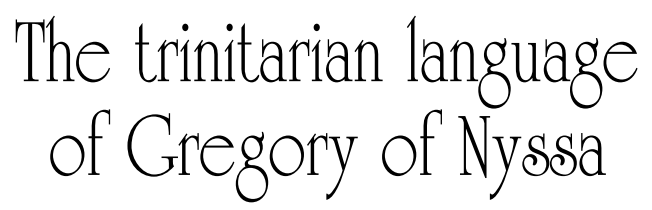

Prof $^{\underline{a}}$ Dr $\stackrel{a}{\underline{a}}$ Ir. Maria Freire da Silva*

Resumo: $\mathrm{O}$ artigo estuda a linguagem trinitária de Gregório de Nissa, denominado Padre da Igreja, intelectual do período patrístico do século IV. Analisa a linguagem do ponto de vista do seu desdobramento naquela época, o conflito entre os aspectos linguísticos de Nissa e Eunômio e sua relevância no confronto com a linguagem teológica atual e a religação dos saberes.

Palavras-chave: Linguagem, Trindade, Relação, Unidade, Distinção.

Abstract: The article studies the Trinitarian language of Gregory of Nyssa, prominent father of the church, intellectual during the Patristic period of the fourth century. Analyze the language from the point of view of their deployment at the time, the conflict between linguistics aspects of Nyssen and Eunomius and their relevance in confrontation with the actual theological language and the re-connection of knowledge.

Key words: Language, Trinity, Relation, Unity, Distinction.

* Bacharel e mestra pela Pontifícia Faculdade de Teologia N. Sra da Assunção São Paulo e doutora em Teologia Dogmática pela Pontifícia Universidade Gregoriana, Roma, Itália. Professora da Faculdade de Teologia da Pontifícia Universidade Católica de São Paulo (PUC-SP), Chefe do Departamento de Teologia Sistemática. São Paulo/Brasil. Membro da Congregação das Irmãs do imaculado Coração de Maria. Contato: freiremaria3@yahoo. com.br. 


\section{Introdução}

Sem dúvida, o século IV constitui um passo decisivo na formulação da doutrina trinitária já que o confronto com as heresias havia obrigado a passar da teologia do logos a da natureza. A separação introduzida entre o mundo criado e a Trindade eterna permite um grande aprofundamento teológico. A negação do grau ontológico intermédio entre Deus e o mundo funda e resultava num equívoco o uso de analogia material na ilustração do dogma.

Trata-se da base da teologia da imagem, que reconhece uma função de culto ao ícone que se torna paradigma do mesmo ato teológico. As disputas trinitárias do século IV podem ser vistas como um confronto entre duas formas de interpretação do prólogo joanino. Ao subordinacionismo que lia o texto joanino a partir da filosofia neoplatônica, se opõe a uma nova teologia da filiação, que partia da afirmação de que Deus é Pai eterno e que Cristo é o Filho eterno encarnado.

Na teologia capadócia é evidente a constante defesa da possibilidade de usar a imagem material para introduzir ao mistério. A mesma formula uma essência e três pessoas, requeria precisão em que sentido os homens são três pessoas e uma única essência.

Este aprofundamento conduziu a um desenvolvimento da reflexão sobre analogias trinitárias que permite recuperar a teologia do Logos. O evangelho de João havia recorrido ao termo Logos para indicar o Filho eterno do Pai. A esse se conjuga o conceito Pneuma para indicar a terceira Pessoa.

Com o desenvolvimento teológico, torna-se necessário aprofundar a teologia das processões, distinguindo a geração da processão. Nesse contexto a analogia trinitária esclarecia a identidade numérica da natureza evitando possível equívoco.

\section{Dados biográficos de Gregório de Nissa}

Nascido em Cesareia da Capadócia, é irmão de São Basílio, dois anos mais novo. Sua iniciadora na vida espiritual será sua irmã Macrina, que depois da morte do pai transformou todas as domiciliares de um dos seus domínios, numa espécie de mosteiro doméstico. Está 
entre os três famosos capadócios, Basílio de Cesareia seu irmão e Gregório Nazianzeno, ambos criadores da linguagem trinitária no século IV, considerados na Teologia como os luminares do Oriente.

Gregório, que só estudou na Capadócia, dominou, no entanto a filo antiga, cujos conceitos transformará radicalmente, tanto estoicos como platônicos, no crisol da revelação. Retórico, esposou Teosébia, mulher de grande cultura e grande fé, o que não o impediu de forma alguma, de se tornar bispo de Nissa, em 371, atendendo um pedido constrangedor de Basílio, que se prevenia contra o poder imperial multiplicando na sua metrópole os bispados e entregando-os a homens de sua confiança. ${ }^{1}$

Homem de caráter meditativo, com grande capacidade de reflexão, de inteligência desperta e aberta, soube mergulhar na cultura de seu tempo. ${ }^{2}$ Nissa é dentre os capadócios, o menos estudado no passado, entretanto, no século XX, o Nisseno passou a ser um dos padres da Igreja mais pesquisados. ${ }^{3}$ Do ponto de vista de Papa a historiografia valoriza as ações de Gregório de Nissa:

Somente a partir da década de 1990 é que percebemos, na bibliografia consultada até o momento, estudos que valorizam as ações do Bispo Gregório de Nissa enquanto autoridade atuante em seu espaço de negociação. ${ }^{4}$

Papa ainda afirma que ao abordar as notícias biográficas de Gregório de Nissa, Ronald E. Heine vincula as importantes atuações do Nisseno nas reuniões eclesiásticas, bem como sua inserção na corte e consequente relação com o Imperador Teodósio e os assuntos político-administrativo-religiosos de seu governo. ${ }^{5}$

1 MORESCHINI, I padri cappadoci, storia, letteratura, teologia, Città Nuova, Roma,2008. P.09.

2 BENEDITO XVI, Los padres de la Iglesia, De Clemente de Roma a san Agustin,Ciudad Nueva, Madrid 2008. P. 119.

3 PAPA, Helena, Amália. O ideal político-religioso niceno na defesa da divindade de Jesus Cristo: considerações iniciais sobre a visão de Gregório de Nissa (séc. IV d.C.), in: Anais do XXVI Simpósio Nacional de História - ANPUH, São Paulo, julho 2011. p. 12.

4 Idem, p. 13.

5 HEINE, R, 1995:(6-7), citado por Papa, in: Anais do XXVI Simpósio Nacional de História - ANPUH, São Paulo, julho 2011. p. 13. 
Nissa "atuou decisivamente no Segundo Concílio Ecumênico em Constantinopla (381) que assinalou o triunfo da ortodoxia trinitária. $\mathrm{Na}$ ocasião, seu nome figurou ao lado dos bispos de Alexandria e de Constantinopla como representantes do 'padrão da fé cristã'”. ${ }^{6}$

Nissa é considerado um dos maiores exegetas do livro Cântico dos Cânticos e o campeão da interpretação alegórica do mesmo. Tal interpretação pertence a sua obra de maturidade teológica com os principais conceitos que caracterizam seu pensamento. ${ }^{7}$

\section{A Linguagem trinitária de Gregório de Nissa}

Gregório de Nissa ${ }^{8}$ trouxe grande contribuição desenvolvendo uma analogia para explicar as duas processões a partir da palavra e do respiro humano. Na oração catequética afirma que em certo sentido a noção de Logos faz parte dos conceitos relativos, pois ao pronunciar o termo Logos se refere imediatamente ao Pai, evitando o erro grego que multiplica os deuses. Demonstra que não há diferença entre o Logos e aquele de quem procede. O desenvolvimento da teologia da phisis permite a Nissa de estender em sentido trinitário a reflexão da teologia do Logos, exposta historicamente ao risco subordinacionista, que pode ser definida à luz da reflexão trinitária do século IV, uma analogia psicológica incompleta.

Isso aprofunda de modo original o resultado em que era comum a tradição Alexandrina e dava uma nova contribuição à discussão sobre a origem da linguagem. Boa parte da obra de Nissa é dedicada à doutrina trinitária. Tende a dar continuidade à reflexão iniciada por Basílio para responder à heresia semiarianista e se interliga posteriormente à questão pneumatômaca, ou seja, à heresia contra a divindade do Espírito Santo.

6 PESTANA, Álvaro, César, Platão e Gregório de Nissa, Letras Clássicas, n. 2, p. 83-114, 1998. Disponível em: http://www.revistas.fflch.usp.br/letrasclassicas/article/viewFile/604/539. Acesso em: 03/03/2014.

7 GREGORIO DI NISSA, Omelie sul cântico dei cantici, EDB, Bologna1995. p. 05.

8 A partir dessa nota, Gregório será citado apenas pelo sobrenome de Nissa. Disponível em: http://bib26.pusc.it/teo/p_maspero/CorsoSSApp3.pdf. Acesso em: 01/03/2014. 
No entanto, Nissa fixa os limites epistemológicos da pesquisa afirmando que para a consciência humana é estruturalmente impossível compreender a natureza divina porque é impercorrível a distância entre a criatura finita e a natureza incriada infinita. Nissa retoma a lição basiliana relativa ao conceito de pensamento humano e segundo o pensamento humano.

A nossa mente colhe qualquer coisa relativamente a Deus: e isso acontece por via negativa ou por via analógica. Aquilo que vem denominado nomes divinos, como geralmente todos os nomes, são invenção do pensamento humano e são posteriores às coisas e a suas atribuições a esse convencional. As vozes são como sombras das coisas e têm a forma correspondendo aos movimentos daquilo que existe. Também os nomes seguem o movimento de Deus suas operações os traços visíveis no criado da potência do Deus invisível.

No entanto, é necessário perceber que o pensamento de Nissa está perpassado da reflexão trinitária, que é o verdadeiro fundamento também de sua teologia espiritual, e, que vem unido à doutrina cristológica. 0 termo Tria aparece, sem dúvida, na teologia de Nissa há uma coincidência entre doutrina trinitária e a compreensão da filiação.

Destarte, o elemento essencial no pensamento de Nissa, que perpassa sua teologia é o apofatismo. Isso é fundamental na sua polêmica contra a Eunômio que negava a consubstancialidade das três Pessoas divinas. Nissa fundamenta sua reflexão trinitária sobre o dado neotestamentário e litúrgico do batismo. A única vida divina é doada através da graça batismal. Dessa forma as Pessoas divinas podem ser conhecidas somente na unidade graças ao sentido pessoal que cada uma imprime a única ação divina. Há um único movimento, uma única comunicação da vontade que do Pai através do Filho se direciona no Espírito Santo.

Há uma dinâmica pericorética na qual as Pessoas são unidas sem confusão no amor recíproco. As três Pessoas são uma única natureza, porque única é a luz, única a vida, e único o fogo de Deus. Para Nissa a Imanência se torna acessível na economia. No nome Cristo vem confessado o mistério trinitário de Deus. Nissa distingue economia e imanência sem separar. Isso corresponde ao pensamento de Irineu 
de Lião que afirma a unidade trinitária da revelação, ou seja, da dimensão econômica.

Já Hilário de Poitiers havia tratado a questão da co-igualdade entre as pessoas divinas afirmando: $\mathrm{O}$ Pai gerou o Filho eternamente sem perder nada de sua natureza, e o Filho recebeu em si tudo do Pai. ${ }^{9}$ Já Gregório Nazianzeno afirma que "a distinção constitui: o Pai é ingênito, o Filho gerado (segundo um princípio lógico e jamais cronológico) e o Espírito Santo procede do Pai sem ser jamais gerado". ${ }^{10}$

Indubitavelmente podemos afirmar que a doutrina trinitária de Nissa resulta profundamente equilibrada, consegue uma elaboração teológica que salvaguarda atentamente a harmonia entre ousia e hipóstases. Põe à luz a divindade do Filho expressando na relação com o Espírito Santo, vínculo do Pai e do Filho, unidade dinâmica da Trindade como mistério de liberdade e de amor. Já Cipriano no III séc. do cristianismo afirma que há unidade nas três Pessoas divinas e que essa mesma unidade deve repercutir na Igreja, no mundo.

Um exemplo evidente desse aprofundamento do aspecto linguístico da questão trinitária é, sem dúvida, elaborado na obra polêmica de Gregório de Nissa contra Eunômio. Polêmica essa já iniciada por seu irmão Basílio na obra eunomiana contra Eunômio. Em particular é o segundo livro que evidencia uma consistente e sistemática reflexão sobre a natureza e sua origem da linguagem.

\section{Gregório de Nissa Contra Eunômio}

Em primeiro lugar, deve-se considerar que após uma argumentação retórica, a argumentação de Nissa segue aproximadamente três partes:

a) a fé ortodoxa e doutrina eunomiana da agnennesia;

b) Os limites da consciência humana e os status dos nomes divinos;

c) argumentos relativos à eternidade;

\footnotetext{
9 MONDIN, Battista, “Ilario di Poitiers”, In: Dizionario dei teologi, ESD, Bologna, 1992. pp. 308-313.

${ }^{10}$ GREGORIO NAZIANZENO, Tutte le orazioni, Bompiani, Milano 2000. p. 747.
} 
Na primeira parte delineia sua posição sustentando a verdadeira divindade de Cristo, contrapondo a posição de Eunômio que afirma a não geração. Na segunda parte, Nissa trata sistematicamente os argumentos que afronta: a pretensão de conhecer a verdade de Deus afirmada por Aécio e Eunômio e negada por Basílio. Nissa apresenta essa como a primeira, dedicando-lhe numerosos parágrafos. ${ }^{11}$

Nissa afirma que quando as Escrituras falam de Deus em termos positivos, se trata de termos de suas operações não de seu Ser. Esse relevo será fecundo na teologia grega posterior. Do ponto de vista de Nissa, Eunômio atribui a Deus uma fala física, provocando um antropomorfismo, esclarecendo que quando a Bíblia diz que Deus conta as estrelas é um antropomorfismo bíblico, para clarear que Deus conhece e controla tudo o que nós não podemos. São os seres humanos que precisam de palavras não Deus.

$\mathrm{Na}$ terceira parte, Nissa trata do uso dos negativos e privativos referentes a Deus, os quais aumentam a consciência humana e são utilizados juntamente com os termos positivos baseados sobre sua atividade.

Do ponto de vista de Moreschini, ${ }^{12}$ Eunômio I trata de questões predominantemente metafísicas e de teologia trinitária, enquanto Eunômio II elabora temas filosóficos da linguagem e Eunômio III apresenta um conteúdo fundamentalmente cristológico. Afirma que Eunômio I e II se distinguem por uma temática tipicamente especulativa e filosófica, Eunômio III recorre largamente á argumentos sobre base escriturística. ${ }^{13}$

O coração da argumentação de Eunômio é a identificação dos termos: "não gerado" ou não geração com a mesma substância de Deus Pai. Não gerado é o termo que indica adequadamente a substância de Deus porque não é atribuído a Deus segundo o pensamento humano: isto advém somente pela realidade finita que se extingue com as palavras que designam. Do mesmo modo o nome gerado indica a substância do Filho que não pode por isso ser a mesma do Pai.

${ }^{11}$ GREGORIO DI NISSA, “Contra Eunumium I et III”, in: Dizionario, Città Nuova, Roma, 2007. pp. 135-146.

12 Idem, 135-146.

${ }^{13}$ Idem, pp. 135-146. 
Sem dúvida, o pensamento de Eunômio desenvolve uma compreensão em termos de simplicidade, outro modo de descrever o Ser divino, sustentando que a não geração não pode ser um conceito como havia suposto Basílio de Cesareia, mas é única e indivisível. Deve-se considerar que o pensamento de Nissa está sistematizado a partir da via apofática, onde o ser humano reconhece sua fragilidade no conhecer a Deus, enquanto, Eunômio parte da argumentação de que a natureza de Deus é conhecida pelo homem assim, como o é ao próprio Deus Essa ideia de Eunômio conflitava tanto com a teologia nicena, quanto com o próprio pensamento de Ário. ${ }^{14}$

Em sua argumentação, Eunômio recorre a uma teoria da linguagem segundo a qual os nomes de origem convencional, do pensamento humano, são flatus vocis que indicam realidades fictícias inexistentes. Os nomes realmente significativos, que indicam a natureza mesma da coisa são anteriores ao homem e são doados por Deus à humanidade juntamente com as coisas mesmas; entre esses nomes próprios, não de origem humana nos é apontado o nome não gerado.

Portanto, Eunômio nega radicalmente a supremacia do Filho e do Espírito Santo com a Pessoa do Pai o que chama de primeiro ser "Supremo e sumamente autêntico". No entanto, negar a supremacia, "o autêntico ser ao Filho, significa negar toda sua existência”. ${ }^{15}$

Do ponto de vista de Jean Daniélou, um entre os primeiros e os grandes estudiosos do pensamento nisseno, afirma que na posição de Eunômio existe certa afinidade com as teses linguísticas da escola neoplatônica de Giamblico. "É iluminador referente a isto confrontar a tese de Eunômio com a afirmação de Giamblico sobre os mistérios egípcios”: "se os nomes não fossem” postos segundo uma convenção não haveria importância pegar um em vez de outro, mas se esses são estreitamente unidos com a natureza dos seres, aqueles que são mais próximos a essa natureza são certamente também os mais gratos aos deuses. Isso aparece claro que a expressão linguística dos povos sacros é preferida por justa razão a dos outros humanos.

\footnotetext{
14 Idem, pp. 135-146.

15 Idem, pp. 135-146.
} 
Em toda teologia capadócia as pessoas divinas se distinguem em suas características individuais de paternidade, filiação e processão. Do ponto de vista de Nissa, o argumento eunomiano, de que algum dos seres divino é simples, e por isso separado, tende a uma compreensão genérica da unidade divina: Deus, afirma Nissa é um Ser único (Substância) com três expressões concretas (Pessoas). ${ }^{16}$

Basílio que sustenta por todos os nomes, também os divinos, a origem convencional, ligada à capacidade heurística do pensamento humano é acusado por Eunômio de pôr um limite ao zelo providencial de Deus, o qual vem negado à atribuição dos nomes as coisas. ${ }^{17}$ Já Evagrio Pontico ${ }^{18}$ aceitava sem dificuldade a fórmula uma ousia e três hipóstases.

Sem dúvida, Nissa é interessado em propor uma exegese adequada dos passos bíblicos que Eunômio e outros arianos interpretavam de forma distorcida. Nissa interpreta textos do AT que tratam a criação da sabedoria uma referência à encarnação econômica, criticando a relação que Eunômio faz entre geração e paixão. Ainda afirma que a geração eterna é totalmente diferente da geração humana, e que o termo Primogênito e Primazia pertencem à encarnação. Recorre dessa forma à distinção entre natureza criada e natureza incriada. Eunômio continua a compreensão de Ário de que o Filho deriva sua condição de excelência da sua qualidade de ser o único gerado diretamente de Deus. Seu caráter mediador é colocado em relevo com acento subordinante. ${ }^{19}$

Nissa trabalha a questão de que a paixão é própria da natureza humana, o Filho de deus sofre a paixão no elemento humano, é o Verbo segundo a carne que cumpre a salvação da humanidade. Dessa forma Nissa aprofunda a questão da communicatio idiomatum. Põe em relevo a dimensão soteriológica da encarnação. ${ }^{20}$

\footnotetext{
${ }^{16}$ Idem, pp. 135-146.

${ }^{17}$ MORESCHINI, Claudio, I Padri cappadoci, storia, letteratura, teologia, Città Nuova, Roma 2008. pp. 248-251.

${ }^{18}$ EVAGRIO PONTICO “Lettera sulla fede, 2, 37”, citado in MORESCHINI, Claudio, I Padri cappadoci, storia, letteratura, teologia, Città Nuova, Roma 2008. pp.283-284.

19 EUNÔMIO, “Exposizione dela fede”, in SIMONETTI, Di M, Il Cristo, vol. 2, Testi Teologici e spirituali in língua greca dal IV al VII secolo, Mondadori, Roma 2009. pp. 184-195.

${ }^{20}$ Idem, pp. 135-146.
} 


\section{Teologia e Economia na Linguagem de Nissa}

Sem dúvida, a teologia de Nissa tem por seu ponto de partida a via econômica e sua "moldura dialógica perpassada pela via apofática".

Do ponto de vista de G. Maspero ${ }^{21} \mathrm{O}$ apofatismo pode ser lido como fundamento daquela epistemologia relacional apoiada em Donato para um diálogo entre teologia e as outras disciplinas. Sem dúvida, o apofatismo do século IV, obrigou a passagem de uma ciência que lê seus objetos como relações. Isto se manifesta na interdição da compreensão da essência, para restituir a linguagem e a consciência ao nível das três hipóstases.

O apofatismo não seria outro que o reflexo gnosiológico da ontologia trinitária, isto é da concepção do primeiro princípio como Pai, Filho e Espírito Santo. Este último, segundo concepção de Nissa, não é simplesmente depois das primeiras duas pessoas, mas ao mesmo tempo conjuntamente, sendo co-igual no ser em relação com as outras duas.

O absoluto são três relações eternas e perfeitamente recíprocas, que a partir da monarquia do Pai origem de todas as coisas, constituem a geração como ato eterno de dom de si da primeira Pessoa ao Filho, o qual é imagem do Pai que se se doa a Ele no Espírito que é o Reino e a glória eterna. Expiração e geração são distintas, porém inseparáveis em relações recíprocas.

A ordem trinitária é preservada graças à passagem ao novo nível ontológico dessa relação recíproca e livre, que supera radicalmente a relação necessária do Logos grego e inaugura a nova lógica trádica exigida na análise fenomenológica de Donato.

O Logos cristão pode estar inserido plenamente na história sem diluir-se, porque é outra história. Transcendência e imanência não são opostas dialeticamente confusas, mas são livres e se doam. ${ }^{22}$

\footnotetext{
${ }^{21}$ MASPERO, G., Ontologia trinitária e sociologia relazionale: due mondi a confronto, PUSC, Roma 2010. Disponível em: http://www.700annidopo.it/attachments/article/72/20101201\%20-\%20Giulio\%20Maspero\%20-\%200ntologia\%20trinitaria\%20e\%20 sociologia\%20relazionale.pdf.

22 Idem, pp. 1-20.
} 
Nesse pensamento a teologia da Cruz e a teologia da glória não se excluem, mas se inter-relacionam uma com a outra. O Deus trinitário é relação e se revela entrando em relação com o ser humano mediante seu Filho. Isso não contradiz o seu ser na kénosis, mas, como se reconhece na contemplação e na profunda análise teológica, revela 0 próprio ser de Deus uno e trino. ${ }^{23}$

Indubitavelmente, A teologia de Gregório de Nissa é:

Apofática no sentido que apófase, nas suas obras, é um instrumento sistemático, como parte de um sistema especulativo por ele construído coerentemente para defender a profissão de fé trinitária. ${ }^{24}$

Se examinarmos a teologia apofática em Gregório, veremos duas noções:

Em primeiro lugar, também, se Gregório recorre habitualmente ao uso do alfa privativo como técnica linguístico epistemológica, e, certamente prefere uma linguagem negativa quando se refere a Deus por abstração, não desenvolve nem se envolve em um método linguístico formalmente conhecido como apófase, o qual é no contexto cristão, um contributo de Pseudo-Dionisio Areopagita. ${ }^{25}$

Desse ponto de vista, "o método linguístico da apófase não pode ser concebido como um elemento constitutivo do seu sistema apofático". ${ }^{26}$ Ainda se pode afirmar que em "segundo lugar, apófase, enquanto instrumento sistemático funciona como princípio teorético compreensivo, que se apoia sobre uma base exegética, mas que na controvérsia trinitária há um contexto importante para um ulterior desenvolvimento sistemático". ${ }^{27}$

Nissa é um autor apaixonado pela Sagrada escritura, faz uma articulação com a filosofia, mas seu objetivo é expor ao máximo as letras da revelação: "Percebe-se, aqui, que o autor em estudo conserva

\footnotetext{
${ }^{23}$ Idem, pp. 1-19.

${ }^{24}$ SILVA, Freire da Maria, "Aspectos escatológicos no pensamento de Gregório de Nissa", in Teocomunicação, v. 43 n. 2, jul./dez. Porto Alegre 2013. p. 245-262.

${ }^{25}$ Idem, p. 245-262.

${ }^{26}$ Idem, p. 245-262.

${ }^{27}$ Idem, p. 245-262.
} 
um estilo elevado em todas as páginas que escreve cheias de imagens e argumentações racionais. Nas suas várias e ricas problemáticas que levanta, faz referência contínua à Sagrada Escritura”. ${ }^{28}$

Nissa leva ao extremo as consequências teológicas o fato de que Cristo é o Novo Adão e que sua ressurreição é causa e o ponto de partida para a ressurreição dos homens, este é o mistério da economia divina. Deus não impediu a morte do homem, porque havia previsto sua ressurreição. ${ }^{29}$

A economia da encarnação tem como centro a morte e a ressurreição de Cristo. Em outras palavras, o mistério pascal de Cristo destrói a morte e se transforma em fonte e princípio de vida nova para a humanidade. A visão escatológica de Gregório é otimista e luminosa: o bem triunfa sobre o mal, é a realização e plenitude do reino de Deus de acordo com que o escreve o evangelista Mateus: "vem a nós o teu reino" (Mt 6, 10).

\section{Considerações finais}

Sem dúvida, a linguagem trinitária de Gregório de Nissa apresenta relevância no que se refere à compreensão do dogma trinitário, mas, também a respeito de sua própria inculturação no saber da época. É uma linguagem capaz de articular razão e fé, com clareza epistemológica e linguística. Nissa contribui com o desenvolvimento do dogma trinitário utilizando as categorias de linguagem de seu tempo, sabendo clarificar as dúvidas dos cristãos frente às controvérsias da heresia neo-arianista.

Há um desafio a ser enfrentado que é o da própria linguagem. Como esclarecer a fé num Deus uno e trino mantendo a monarquia divina, inserido numa sociedade prenhe de visões politeístas. Indubitavelmente, Nissa traz uma grande contribuição à teologia moderna e

\footnotetext{
${ }^{28}$ BOFF, L, \& MORAES, A, R, “A concepção de vida em Gregório de Nissa Ensaio de aproximações com as ciências da Vida”. In: Atualidade Teológica, ano XII, n. 28, janeiro/abril, PUCRJ, 2008. pp. 137-168.

${ }^{29}$ MATEO-SECO, L. F; art. “Escatologia”, in: Dizionario, Gregorio di Nissa, Ed. Città Nuova, Roma 2007. pp. 251-263.
} 
pós-moderna que é a capacidade de trabalhar a linguagem teológica dialogando com os diversos saberes.

Ainda contribui com a forma como apresenta a inter-relação entre teologia e economia de forma pericoretizada. Demonstra também a potencialidade da teologia na articulação com os saberes, e, a necessidade de sua relevância na sociedade. Destarte, não se pode ignorar que seu pensamento teológico situa-se no espaço comunitário de exortação à fé da comunidade e, social-político de esclarecimento da verdade de fé e de suas implicações moral e ética.

Sem dúvida, não se pode ignorar a contribuição juntamente com outros padres da Igreja, na compreensão da linguagem como se pode citar Gregório Nazianzeno que contribui com a abordagem eclesiológica do Concílio Vaticano II. ${ }^{30}$

Indubitavelmente, a linguagem de Nissa é de imensa relevância tanto em nível da teologia trinitária quanto do ponto de vista do seu desenvolvimento da teologia místico-espiritual. Nissa se insere no itinerário teológico do Século IV o qual pode representar uma dimensão dialógica ligada também a questão antropológica tão necessária ao homem pós-moderno tão alheio à linguagem sobre o divino.

\section{Bibliografia}

BENEDITO XVI, Los padres de la Iglesia, De Clemente de Roma a san Agustin, Ciudad Nueva, Madrid 2008.

BOFF, L. \& MORAES, A. R. "A concepção de vida em Gregório de Nissa Ensaio de aproximações com as ciências da Vida”, in: Atualidade Teológica, ano XII, n. 28, janeiro/abril, PUCRJ, 2008.

GREGORIO NAZIANZENO, Tutte le orazioni, Bompiani, Milano 2000. p. 747. GREGORIO DI NISSA, “Contra Eunumium I et III”, in: Dizionario, Città Nuova, Roma 2007. pp. 135-146.

GREGORIO DI NISSA, Omelie sul cântico dei cantici, EDB, Bologna1995. MORESCHINI, Claudio, I Padri cappadoci, storia, letteratura, teologia, Città Nuova, Roma 2008. pp. 248-251.

${ }^{30}$ GIANOTTI, D, I padri dela Chiesa al concilio vaticano II: la teologia patrística nella lumen gentium, EDB, Bologna 2010. pp. 139-41. 
PAPA, Helena, Amália. Considerações iniciais sobre a visão de Gregório de Nissa. O ideal político-religioso niceno na defesa da divindade de Jesus Cristo: (séc. IV d.C.), in Anais do XXVI Simpósio Nacional de História ANPUH, São Paulo, julho 2011. p. 12. HEINE, R. 1995:6-7), citado por Papa in: Anais do XXVI Simpósio Nacional de História - ANPUH - São Paulo, julho 2011. p. 13.

PESTANA, Álvaro, César, Platão e Gregório de Nissa, Letras Clássicas, n. 2, p. 83-114, 1998. Disponível em: http://www.revistas.fflch.usp.br/letrasclassicas/article/viewFile/604/539. Acesso em: 03/03/2014.

MONDIN, Battista, "Ilario di Poitiers", in: Dizionario dei teologi, ESD, Bologna, 1992. pp. 308-313.

EUNÔMIO, “Exposizione dela fede”, in SIMONETTI, Di M, Il Cristo, vol. 2, Testi Teologici e spirituali in língua greca dal IV al VII secolo, Mondadori, Roma 2009. pp. 184-195.

MASPERO, G, Ontologia trinitária e sociologia relazionale: due mondi a confronto, PUSC, Roma,2010.http://www.700annidopo.it/attachments/ article/72/20101201\%20/20Giulio\%20Maspero\%20\%20ntologia trinitaria e sociologia relazionale.pdf. Acesso em: 28/02/2014.

SILVA, Freire da Maria, "Aspectos escatológicos no pensamento de Gregório de Nissa”, in: Teocomunicação, v. 43 n. 2, jul./dez. Porto Alegre 2013. p. 245-262.

GREGORIO NAZIANZENO, Tutte le orazioni, Bompiani, Milano 2000. p. 747. GREGORIO DI NISSA, “Contra Eunumium I et III”, in: Dizionario, Città Nuova, Roma 2007. pp. 135-146.

MORESCHINI, Claudio, I Padri cappadoci, storia, letteratura, teologia, Città Nuova, Roma 2008. pp. 248-251.

PAPA, Helena, Amália. 0 ideal político-religioso niceno na defesa da divindade de Jesus Cristo: considerações iniciais sobre a visão de Gregório de Nissa (séc. IV d.C.), in: Anais do XXVI Simpósio Nacional de História -ANPUH - São Paulo, julho 2011. p. 12. HEINE, R. 1995:6-7), citado por Papa in: Anais do XXVI Simpósio Nacional de História - ANPUH - São Paulo, julho 2011. p. 13.

PESTANA, Álvaro, César, Platão e Gregório de Nissa, Letras Clássicas, n. 2, p. 83-114, 1998. In: http://www.revistas.fflch.usp.br/letrasclassicas/ article/viewFile/604/539, disponível em 03/03/2014. A partir dessa nota, Gregório será citado apenas pelo sobrenome de Nissa. http://bib26.pusc. it/teo/p_maspero/CorsoSSApp3.pdf. Acesso em: 01/03/2014.

MONDIN, Battista," Ilario di Poitiers”, In: Dizionario dei teologi, ESD, Bologna, 1992. pp. 308-313. 
EUNÔMIO, “Exposizione dela fede”, in: SIMONETTI, Di M, Il Cristo, vol. 2, Testi Teologici e spirituali in língua greca dal IV al VII secolo, Mondadori, Roma 2009. pp. 184-195. Idem, pp. 135-146.

MASPERO, G., Ontologia trinitária e sociologia relazionale: due mondi a confronto, PUSC, Roma 2010. http://www.700annidopo.it/attachments/ article/72/20101201\%20-\%20Giulio\%20Maspero\%20-\%200ntologia\%20 trinitaria\%20e\%20sociologia\%20relazionale.pdf.

SILVA, da Freire Maria, "Aspectos escatológicos no pensamento de Gregório de Nissa” in: Teocomunicação, v. 43 n. 2, jul./dez. Porto Alegre 2013. p. 245-262. 